OPEN ACCESS

Edited by:

Du Yuan,

Nanyang Technological

University, Singapore

Reviewed by:

Jin Zhao,

Nanjing University of Posts and Telecommunications, China

Xiaolei Huang,

Northwestern Polytechnical

University, China

${ }^{*}$ Correspondence:

Yang Gui

guiyang@wust.edu.cn

Specialty section:

This article was submitted to

Electrochemistry,

a section of the journal

Frontiers in Chemistry

Received: 02 July 2020 Accepted: 05 August 2020

Published: 23 October 2020

Citation:

Gui Y, Lei Y and Fan BA (2020) Investigation on the Effect of Different

Mild Acidic Electrolyte on ZIBS

Electrode/Electrolyte Interface and the

Performance Improvements With the

Optimized Cathode

Front. Chem. 8:827.

doi: 10.3389/fchem.2020.00827

\section{Investigation on the Effect of Different Mild Acidic Electrolyte on ZIBs Electrode/Electrolyte Interface and the Performance Improvements With the Optimized Cathode}

\author{
Yang Gui ${ }^{*}$, Yang Lei and Bao An Fan \\ Key Laboratory of Hubei Province for Coal Conversion and New Carbon Materials, School of Chemistry and Chemical \\ Engineering, Wuhan University of Science and Technology, Wuhan, China
}

Zinc ion batteries (ZIBs), as promising alternatives of lithium ion batteries (LIBs), have aroused revived interest in the energy storage field recently. To obtain good performance, the choice of electrolyte plays a vital role. Therefore, in this work, three kinds of aqueous electrolyte have been assessed for interfacial effect and ZIB performance. Through the comparison, $\mathrm{ZnSO}_{4}$ electrolyte showed advantages on ionic conductivity over both $\mathrm{Zn}\left(\mathrm{NO}_{3}\right)_{2}$ and $\mathrm{Zn}\left(\mathrm{CH}_{3} \mathrm{COO}\right)_{2}$ solution, $\mathrm{Zn}\left(\mathrm{CH}_{3} \mathrm{COO}\right)_{2}$ exhibited considerable $\mathrm{Zn}$ stripping/plating kinetics with $\mathrm{ZnSO}_{4}$, and there was no characteristic peak pair of $\mathrm{Zn}$ dissolution/deposition found in $\mathrm{Zn}\left(\mathrm{NO}_{3}\right)_{2}$. Additionally, a lower charge transfer resistance was proved when the cell with $1 \mathrm{M} \mathrm{ZnSO}_{4}$ solution. Besides, to further study on cathodic graphite paper, activation and optimization has been conducted, and cells with optimized graphite paper showed an outstanding enhancement.

Keywords: aqueous electrolye, interfacial effect, ZIB performance, electrochemical assessment, Zn stripping/plating kinetics

\section{INTRODUCTION}

Nowadays, different types of rechargeable batteries, as lithium-ion battery (LIB) alternatives, have attracted attention of researchers due to that (1) limited sources of lithium; (2) higher flammable risk of organic electrolyte in LIBs; (3) high chemical activity of lithium leading to a harsh requirement on its preparation process (Whittingham, 2004; Armand and Tarascon, 2008). Therefore, it is significant to search for new ion battery resources with considerable or even higher capacity but much safer and convenient fabrication methods. Systems built up on elements with electropositive characters such as $\mathrm{Na}, \mathrm{Mg}, \mathrm{Al}, \mathrm{Ca}$, and $\mathrm{Zn}$ have attracted extensive interest because of promising theoretical capacity, abundant material and effective cost (Li et al., 2014; Muldoon et al., 2014; Yabuuchi et al., 2014; Lin et al., 2015; Choi and Aurbach, 2016; Ponrouch et al., 2016; Zhang et al., 2016). Meanwhile, replacing the organic electrolyte with an aqueous one offers advantages including more convenient manufacturing conditions as well as advantageous cost, greener, safer, and better ionic conductivity (Lu et al., 2011; Kim et al., 2014). Regarding these superior features, aqueous $\mathrm{Zn}$-ion battery (ZIB)/capacitor (ZIC) technology plays a particular role as a promising alternative based on its property of good water compatibility, low flammability and, especially when compared with LIBs, Zn exhibits higher charge density (Lee et al., 2015; Pan et al., 2016). 
Following the development history of ZIBs, the first ZIB prototype was made in 1999 by using zinc metal as electrode and alkaline as electrolyte which presented excellent characters of low redox potential $[-0.76 \mathrm{~V}$ vs. standard hydrogen electrode (SHE)]. Since then, Zinc metal has been applied widely in different batteries like Ni-Zn battery, $\mathrm{MnO}_{2}-\mathrm{Zn}$ battery, Zinc ion battery, and Zinc air battery (Yang and Lin, 2002; Cheng et al., 2005). However, the sever zinc dendrite formation in alkaline solution extremely shortened its cycling life and limited the corresponding discharge capacity. To deal with this problem, the displacement of alkaline electrolyte with mild solution of zinc sulfate was firstly investigated by Yamamoto and Shoji (1986). According to the observation, due to mild acidic condition, the appearance of $\mathrm{ZnO}, \mathrm{Zn}(\mathrm{OH})_{2}$, etc. by-products on zinc anode has been effectively inhibited (Yamamoto and Shoji, 1986). Hence, the choice of electrolyte plays a vital role for the overall performance of ZIBs. Firstly, the function of the electrolyte does not only provide pathways for ion migration but also determines the reversibility of $\mathrm{Zn}$ plating/stripping process and SEI formation (Wang F. et al., 2018; Wang Z. et al., 2018; Qiu et al., 2019; Yuan et al., 2019; Zhao et al., 2019). Secondly, the accurate choice of electrolyte, including its concentration, $\mathrm{pH}$ value, coordination number and so on, could maximize the energy storage capacity of the whole system to achieve its optimized performance (Li et al., 2016; Wang F. et al., 2018; Wang Z. et al., 2018; Zhao et al., 2018). Up to now, the exploration on electrolytes for ZIBs is still in its infancy, and more details on the understanding of the effect of electrolytes on the electrochemical performance is required. In this paper, to reveal the relationship between electrolyte and zinc storage performance, we investigated three kinds of electrolyte by using zinc and graphite paper as counter and working electrode, respectively, from the perspectives of stripping/plating kinetics, interfacial kinetics, and its behavior on zinc storage performance. Furthermore, cathode optimization has been designed as well and harvested outstanding enhancement on ZIB performance.

\section{EXPERIMENTS}

\section{Chemicals and Materials}

Zinc acetate dihydrate (ALADDIN); Zinc nitrate hexahydrate (ALADDIN); Zinc sulfate monohydrate (ALADDIN); Ethanol (ALADDIN); concentrated sulfuric acid (ALADDIN); Acetone $($ ALADDIN). Zn plate $(34 \times 150 \times 0.2 \mathrm{~mm})$; Graphite paper $(125$ $\times 200 \times 0.1 \mathrm{~mm})$.

\section{Material Pretreatment}

Zn plate was cut into a dimension of $34 \times 25 \times 0.2 \mathrm{~mm}$, then placed into a mixture solution of ethanol and acetone with a volume ratio of $1: 1$, followed by exposure to an ultrasound bath for $15 \mathrm{~min}$, after that the sample was taken out and readied for later use. The graphite paper wascut into a dimension of $30 \times 20$ $\times 0.1 \mathrm{~mm}$ and cleaned with acetone.

The activation of graphite paper was realized by exposing one clean piece of graphite paper in a three-electrode system at a constant potential for a certain period. The potential sweep rate was set at $0.01 \mathrm{~V} \mathrm{~s}^{-1}$. The system was constructed by a piece of graphite paper, platinum foil, and saturated calomel (SCE) as working, counter, and reference electrode, respectively. The electrolyte was composed by $2 \mathrm{M} \mathrm{H}_{2} \mathrm{SO}_{4}$. Five samples were prepared and named as S1, S2, S3, S4, and S5, respectively. S1 was treated by exposing one piece of graphite paper in $2 \mathrm{M} \mathrm{H}_{2} \mathrm{SO}_{4}$ under $4 \mathrm{~V}$ for $60 \mathrm{~s}$. When the treatment was finished, S1 was taken out and flushed by DI water until $\mathrm{pH}$ of the solution close to $\sim 6.7$ ( $\mathrm{pH}$ value of the DI water), then placed in an oven at $60^{\circ}$ overnight. The treatment condition for S2 was the same as S1 except the final potential at $6 \mathrm{~V}$ for a period of $300 \mathrm{~s}$. S3 and S4 was treated at $6 \mathrm{~V}$ as well but within a period of 450 and $600 \mathrm{~s}$ independently. S5 was activated at $8 \mathrm{~V}$ for $450 \mathrm{~s}$.

\section{Electrochemical Tests}

\section{Three Electrode System Measurement}

The testing system was constructed by a piece of graphite paper with a dimension of $2 \times 3 \mathrm{~cm}^{2}$ as the working electrode, a piece of $\mathrm{Zn}$ plate $\left(2.5 \times 3.5 \mathrm{~cm}^{2}\right)$ as the counter electrode and another piece of $\mathrm{Zn}$ plate $\left(2.5 \times 3.5 \mathrm{~cm}^{2}\right)$ as the reference electrode. The series of cyclic voltammograms (CVs) in different electrolytes were recorded at a potential sweep rate of $1 \mathrm{mV} \mathrm{s}^{-1}$ within a proper electrochemical window. Electrochemical impedance spectroscopy (EIS) measurement was conducted through a CHI600E electrochemical workstate with an AC voltage of $5 \mathrm{mV}$ amplitude in the frequency ranging from $100 \mathrm{kHz}$ to 100 $\mathrm{mHz}$. This measurement was used to differentiate the effect on different electrolyte on electrode interfaces when considering a ZIB performance.

\section{Two Electrode System Measurement}

The two-electrode system consisted of using a CR2032 cointype. CR2032 coin cell was assembled by the pristine or activated graphite paper as a working electrode, $\mathrm{Zn}$ foil as a counter electrode, filter paper as a membrane and $1 \mathrm{M} \mathrm{ZnSO}_{4}$ as an electrolyte. The galvanostatic charge/discharge performance of the cell has been conducted by a LAND-CT2001A batterytesting instrument.

\section{Morphology Characterization}

Scanning electron microscopy (SEM) was taken by Nova NanoSEM400 microscopes equipped with energy dispersive spectroscopy (EDS) for elemental analysis.

\section{RESULTS AND DISCUSSION}

A three-electrode system consisting of $\mathrm{Zn} / \mathrm{Zn} /$ graphite paper as counter/reference/working electrode wasbuilt up. Three kinds of electrolytes havebeen selected. As shown in Figure 1, the cyclic voltammetry in $\mathrm{Zn}\left(\mathrm{CH}_{3} \mathrm{COO}\right)_{2}$ and $\mathrm{ZnSO}_{4}$ electrolyte reveals an obvious reversible electrochemical stripping/plating process of $\mathrm{Zn}$ (Xu et al., 2012; Li et al., 2016). However, no characteristic peak pair corresponding to $\mathrm{Zn}$ dissolution/deposition has been found in $1 \mathrm{M} \mathrm{Zn}\left(\mathrm{NO}_{3}\right)_{2}$ due to the instability of $\mathrm{NO}_{3}^{-}$(Zhang et al., 2016). Notably, the onset potential for deposition/dissolution of $\mathrm{Zn}$ plating/stripping is $-0.13 /-0.034 \mathrm{~V}$ and $-0.11 /-0.055$ corresponding to $\mathrm{Zn}\left(\mathrm{CH}_{3} \mathrm{COO}\right)_{2}$ and $\mathrm{ZnSO}_{4}$ separately (Liu et al., 2016, 2017). Compared with $\mathrm{ZnSO}_{4}$, a 
smaller potential separation was observed in $\mathrm{Zn}\left(\mathrm{CH}_{3} \mathrm{COO}\right)_{2}$ which reflects better reversibility. Furthermore, a lower oxidation peak at around $0.48 \mathrm{~V}$ is suspected due to the oxidation of

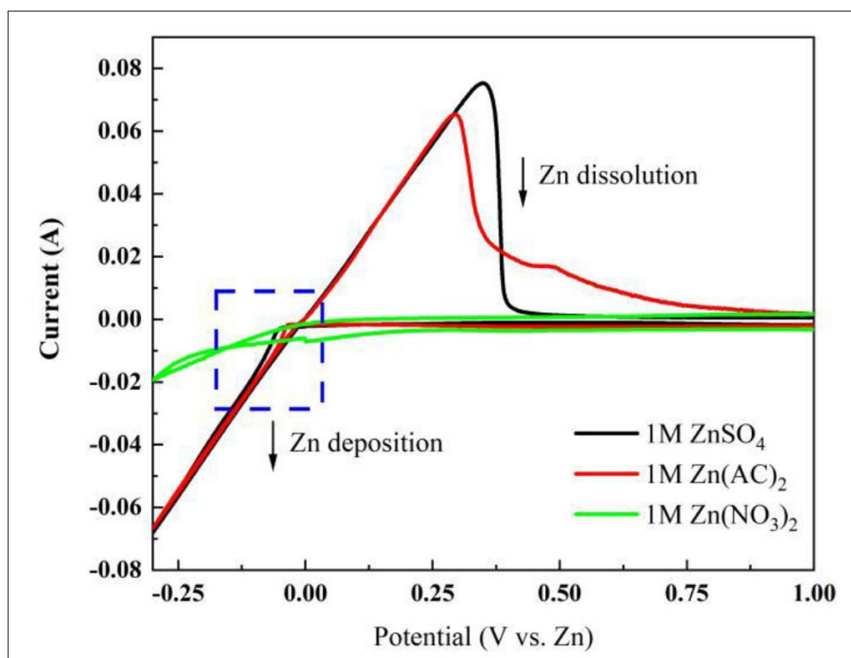

FIGURE 1 | Cyclic voltammetry characterization in a three-electrode system at a scan rate of $1 \mathrm{mV} \mathrm{s}^{-1}$ in different electrolytes.
$\mathrm{CH}_{3} \mathrm{COO}^{-}$. However, the higher current density exhibited in $\mathrm{ZnSO}_{4}$ solution assists a faster kinetics. Therefore, from the cyclic voltammetry analysis on these three electrolytes, it is concluded that (1) there is no obvious $\mathrm{Zn}$ stripping/plating process captured in $1 \mathrm{M} \mathrm{Zn}\left(\mathrm{NO}_{3}\right)_{2}$ electrolyte at the corresponding electrochemical reactive potential range; (2) relative to $1 \mathrm{M}$ $\mathrm{Zn}\left(\mathrm{CH}_{3} \mathrm{COO}\right)_{2}$ solution, the system in $1 \mathrm{M} \mathrm{ZnSO}_{4}$ behaves faster kinetics of $\mathrm{Zn}$ dissolution/deposition.

To further investigate the interface effects between the electrolyte and electrode surface, an electrochemical impedance spectrum (EIS) was designed. The measurement was set at open circuit potential with respect to the chosen three electrolytes as shown in Figure 2. In their Nyquist plots in Figure 2A, through the inset image, a depressed semicircle in the highfrequency region can be seen in all these three electrolytes. In further detail, the cross section at the $\mathrm{X}$-axis tells resistance difference due to the different ionic conductivity of respective electrolyte (Hwang, 2018). Hence, the result may indicate an ionic conductive sequence of $1 \mathrm{M} \mathrm{ZnSO}_{4}, 1 \mathrm{M} \mathrm{Zn}\left(\mathrm{CH}_{3} \mathrm{COO}\right)_{2}$ and $1 \mathrm{M} \mathrm{Zn}\left(\mathrm{NO}_{3}\right)_{2}$ from high to low. In addition, the highest imaginary point of the enlarged semicircle in the high-frequency region corresponds to the phase transition in their Bode plots in Figure 2B (Wang et al., 2001), which represents a charge transfer process involving stripping/plating of $\mathrm{Zn} / \mathrm{Zn}^{2+}$. Based on their characteristic frequencies, the lowest one corresponds
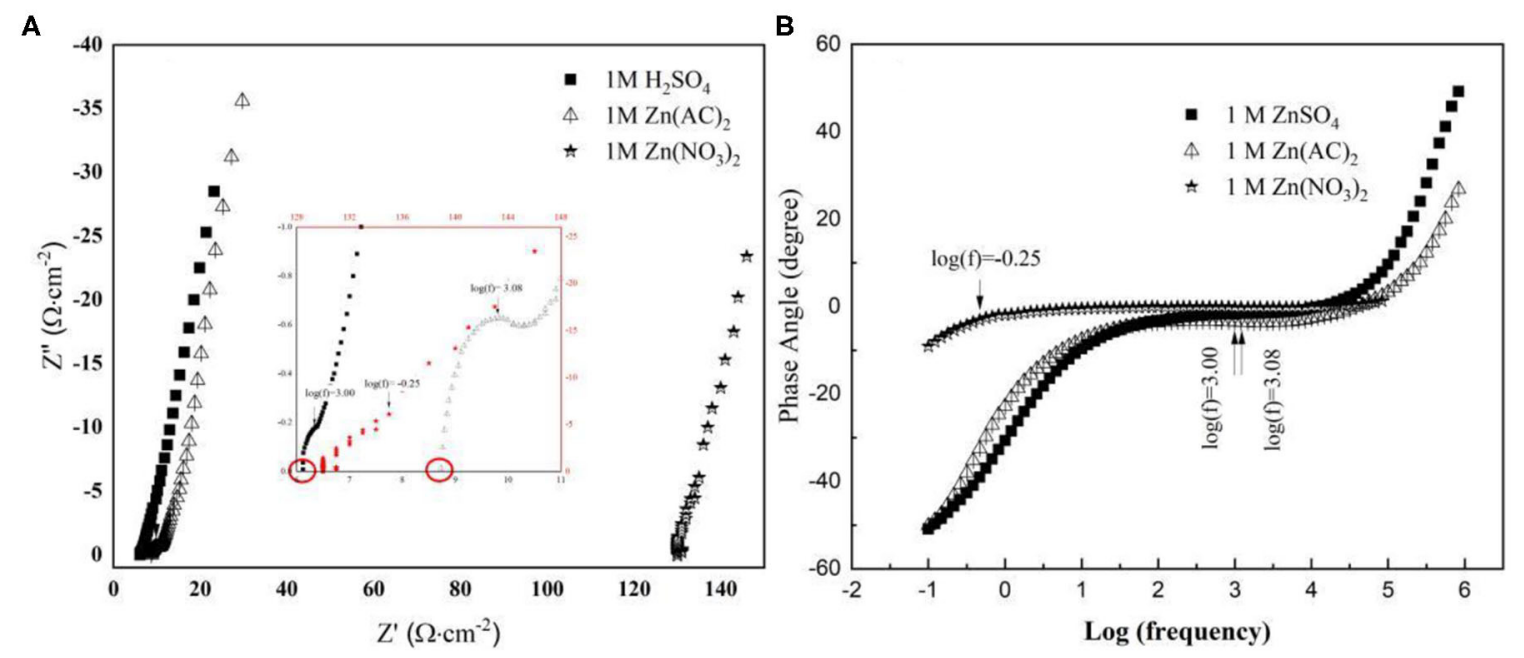

C

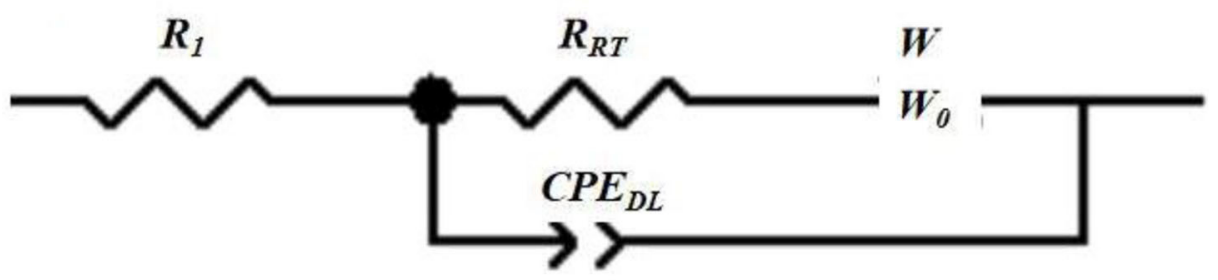

FIGURE 2 | (A) EIS Nyquist plots and Bode plots (B) collected from a three-electrode system with different electrolyte; (C) Equivalent Circuit for data fitting. 
to $1 \mathrm{M} \mathrm{Zn}\left(\mathrm{NO}_{3}\right)_{2}$ and indicates a slower kinetics while the other two show higher kinetics, which is in agreement with their cyclic voltammetry observation. Furthermore, the platform extended farthest to $60^{\circ}$ describes a diffusion process, which is characterized by the size of warburg. The size of warburg time constant is inversely proportional to the square-root of $\mathrm{Zn}^{2+}$ diffusivity (Gui and Blackwood, 2015). The fitting results based on the equivalent circuit displayed in Figure 2C were listed in Table 1, where $R_{s}$ represents the series resistance originated from electrode, electrolyte, and the contact; $C P E_{D L}$ denotes a constant phase element designating the double layer capacitance arising from the charges accumulated on the surface of electrode; $R_{C T}$ is the resistance produced by the charge transfer process from the electrolyte to $\mathrm{Zn}$ surface, which also associates with this process kinetics; and $W o$ is symbolized as an open circuit Warburg impedance reflecting ion diffusion from electrolyte to the electrode/electrolyte interface. From Table 1, the series resistance in $1 \mathrm{M} \mathrm{ZnSO}_{4}$ is the lowest and the highest one is assigned to $1 \mathrm{M} \mathrm{Zn}\left(\mathrm{NO}_{3}\right)_{2}$, which is suspected to be caused by the different solvation condition in different electrolytes and further the various ionic conductivity. From this aspect, it means that $\mathrm{ZnSO}_{4}$ solution should be the most preferred electrolyte with favorable ionic conductivity, hence benefit for ions diffusion. Simultaneously, the value of $R_{C T}$ also keeps the same sequence with $R s$. The smaller charge transfer resistance in $\mathrm{ZnSO}_{4}$ demonstrates a faster kinetics which is consistent with the anodic current density recorded in Figure 1. Additionally, a highest value of $C P E_{D L}$ in $1 \mathrm{M} \mathrm{ZnSO}_{4}$ electrolyte was captured as well which could be due to the faster charge transfer kinetics making a rougher surface of the $\mathrm{Zn}$ electrode. However, the system with $1 \mathrm{M} \mathrm{ZnSO}_{4}$ exhibits the longest time period for ions diffusion onto electrode surface that may indicate a longer path length the ions in $1 \mathrm{M} \mathrm{ZnSO}_{4}$ will travel. This elongation may be due to the formation of $\mathrm{Zn}(\mathrm{OH})_{\mathrm{x}}\left(\mathrm{SO}_{4}\right)_{\mathrm{y}} \cdot \mathrm{zH}_{2} \mathrm{O}$ on the electrode surface which takes up the near surface for ions to reach and a further study on SEI on $\mathrm{Zn}$ has to be designed to clear the observation (Lee et al., 2016; Pan et al., 2016; Parker et al., 2017).

To explore the impact of different electrolytes on ZIB performance, CVs of the coin cell with different electrolytes has been performed. The coin cell was constructed by $\mathrm{Zn}$ foil and non-activated graphite paper as a counter and working electrode separately. From Figure 3A, shapes of CVs for both $1 \mathrm{M} \mathrm{Zn}\left(\mathrm{CH}_{3} \mathrm{COO}\right)_{2}$ and $1 \mathrm{M} \mathrm{Zn}\left(\mathrm{NO}_{3}\right)_{2}$ are almost the same as in a three-electrode system, but a sharp decrease on the deposition/dissolution peak pair was observed for a coin cell with $1 \mathrm{M} \mathrm{ZnSO}_{4}$ electrolyte, which could be due to formation of a surface layer (Konarov et al., 2018). Additionally, the cyclic shapes enclosed from 0.8 to $2.0 \mathrm{~V}$ for the three electrolytes are all close to rectangular, which can be contributed to by the capacitive property of the graphite paper. Furthermore, the ratio of anodic area over its correlated cathodic one is closer to 1 in $1 \mathrm{M} \mathrm{ZnSO}_{4}$. This good symmetric behavior implies a better reversibility. In order to reveal the impact of these chosen electrolytes on ZIBs performance, the respective charge/discharge polarization curves at a current density of $0.02 \mathrm{~A} \mathrm{~g}^{-1}$ has been collected and shown in Figure 3B. The overall specific capacities of the ZIBs are low due to the low surface area of the working electrodes, i.e., the graphite papers. Even though, under the same condition, the different behaviors due to various electrolytes are still distinguishable. Figure 3B points out that the $\mathrm{ZIB}$ with $1 \mathrm{M} \mathrm{ZnSO}_{4}$ performs the highest potential on the electrochemical energy storage capacity. Besides, the good symmetry of its charge/discharge polarization curve reflects the high coulomb efficiency, which is consistent with its symmetric cyclic voltammetry curve. However, coulomb efficiencies of the $\mathrm{ZIBs}$ with $1 \mathrm{M} \mathrm{Zn}\left(\mathrm{NO}_{3}\right)_{2}$ and $\mathrm{Zn}\left(\mathrm{CH}_{3} \mathrm{COO}\right)_{2}$ are only 47.4 and $64.8 \%$ individually.

Based on Figure 3B, realizing the poor performance by the non-activated surface of the graphite paper, electro-activation method has been adopted to activate the graphite paper surface. The respective treatment condition for samples of S1, S2, S3, S4, and S5 was stated in the experiment section. To visualize the effect of the activation result, SEM images have been collected and displayed in Figure 4. Through the comparison, from S1 to $\mathrm{S} 5$, there are more and more folds on the graphite paper surface as compared with pristine graphite paper in Figure 4A. The larger rugae area reflects an increased surface area. Hence, it is supposed to harvest enhanced ion storage capability when assembled in an ZIB cell. Meanwhile, we found that the treatment was sensitive to potential rather than the exposure time. As can be seen that the surface of $\mathrm{S} 1$ in Figure $4 \mathrm{~B}$ is much smoother than $\mathrm{S} 3$ in Figure 4D. Even though, unlike S4 and S5, the surface of S3 still keeps as a whole with shallow wrinkles rather than fractures in Figures 4E,F. Accordingly, all samples show a certain degree of surface oxidization and sulfidation based on their EDS analysis. The overall content of oxygen is higher than sulfur (at. 12 vs. at. $2 \%$ on average) which was donated by $\mathrm{SO}_{4}^{2-}$.

To discuss the effects of activated graphite papers (AGP) on ZIB performance, CVs of the coin cell with non-activated (pristine GP) and different activated graphite paper (AGP) as cathode has been measured and compared. Figure 5A displays the $\mathrm{CV}$ curves of coin cells at $1 \mathrm{mV} \mathrm{s}^{-1}$. As compared to the $\mathrm{CV}$ of

TABLE 1 | Fitting results list based on the equivalent circuit in Figure 2C.

\begin{tabular}{|c|c|c|c|c|c|c|}
\hline $\begin{array}{l}\text { System with } \\
\text { different } \\
\text { electrolyte }\end{array}$ & $R_{s}\left(\Omega \mathrm{cm}^{-2}\right)$ & $\begin{array}{c}R_{C T}(\Omega \\
\left.\mathrm{cm}^{-2}\right)\end{array}$ & \multicolumn{2}{|c|}{$w$} & \multicolumn{2}{|c|}{$C P E_{D L}\left(\mathrm{~F} \mathrm{~cm}^{-2}\right)$} \\
\hline $1 \mathrm{M} \mathrm{Zn}\left(\mathrm{CH}_{3} \mathrm{COO}\right)_{2}$ & 8.82 & 0.82 & 0.35 & 0.12 & $9.90 \times 10^{-6}$ & 1.00 \\
\hline $1 \mathrm{M} \mathrm{Zn}\left(\mathrm{NO}_{3}\right)_{2}$ & 126.44 & 3.03 & 0.61 & 11.72 & $3.15 \times 10^{-6}$ & 0.65 \\
\hline
\end{tabular}


A

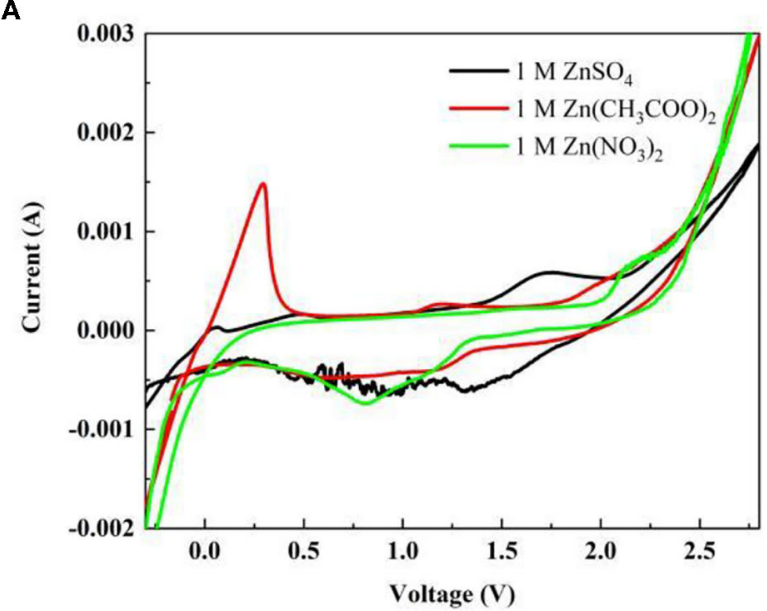

B

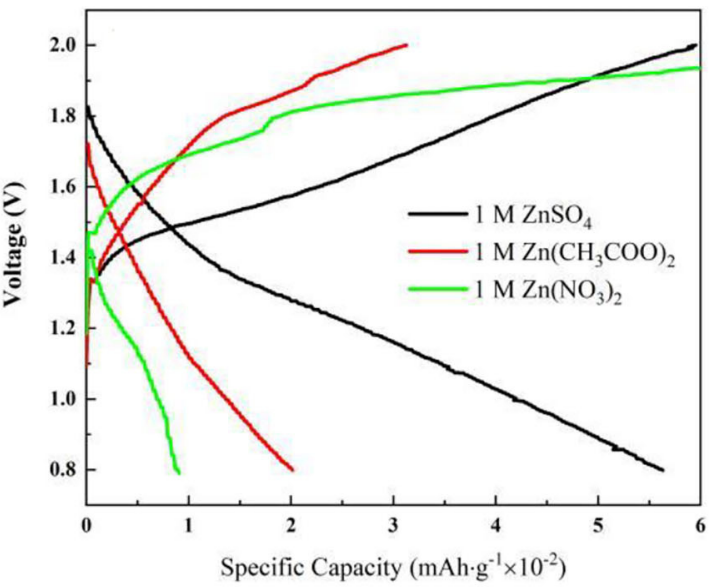

FIGURE 3 | (A) Electrode Electrochemical performance characterization in different electrolyte using coin cell construction: (A) Cyclic voltammetry (CV) of coin cells at a scan rate of $1 \mathrm{mV} \mathrm{s}^{-1}$; (B) Galvanostatic charge/discharge curves of coin cells at a current density of $0.02 \mathrm{~A} \mathrm{~g}^{-1}$.
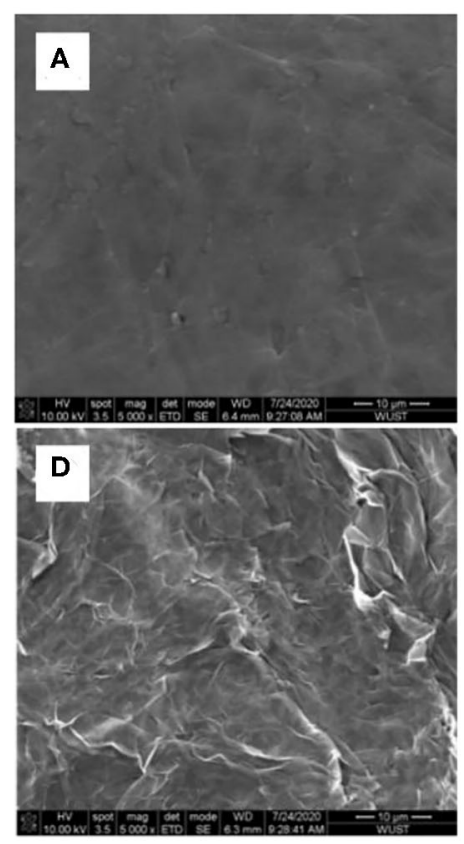
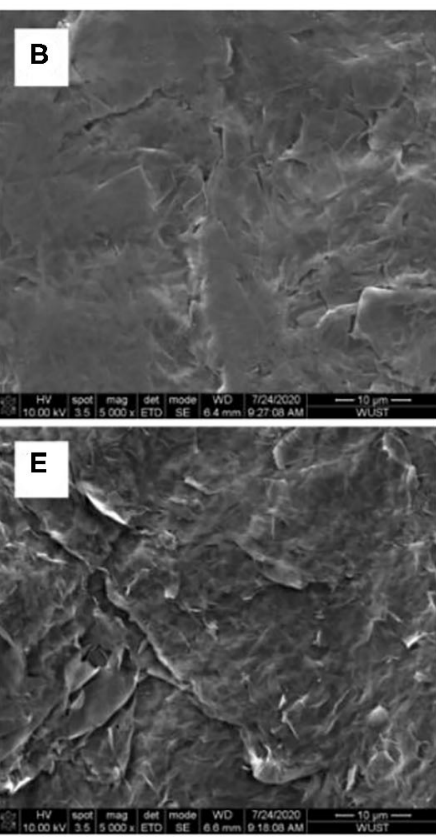
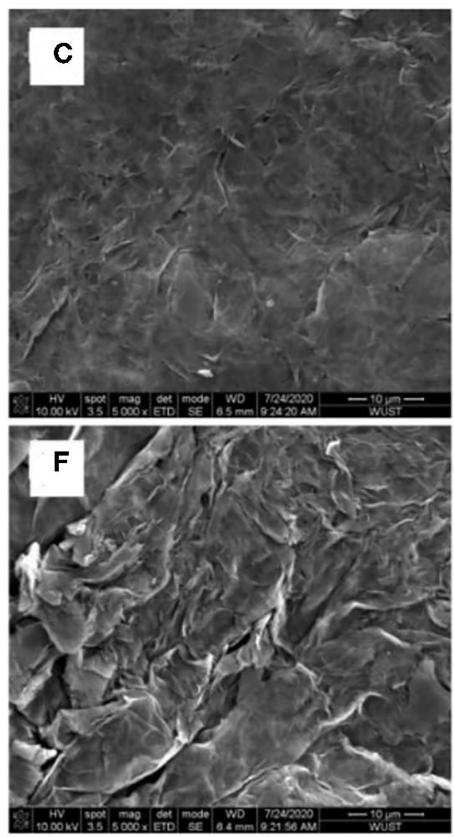

FIGURE 4 | SEM images of (A) pristine graphite paper, (B) S1, (C) S2, (D) S3, (E) S4, and (F) S5.

the cell with non-activated graphite paper (NAGP), the observed anodic peak in all cells with AGP migrates more negatively, which could be related to the electrode activation effects, similar to the observation of the initial profile changes in $\mathrm{MnO}_{2}$-based cathodes in ZIBs (Zhang et al., 2016). Further comparison finds that during the anodic sweeping, peaks centered at 1.55 and $1.50 \mathrm{~V}$ for S1 and S2, respectively, become sharp at 1.62, 1.67, and $1.7 \mathrm{~V}$ in $\mathrm{CV}$ of S3, S4, and S5 separately. The change is suspected to be induced by anions $\left(\mathrm{SO}_{4}^{2-}\right)$ intercalation into graphite interlayers as discussed in zinc graphite battery (Fan et al., 2019). Moreover, through comparing the half peak width and anodic current density, the anodic peak located at $1.62 \mathrm{~V}$ shows the narrowest and highest, which implies a faster kinetic process on S3 interface than on the others'. In cathodic scan, a large cathodic peak centered at 1.29 and $1.34 \mathrm{~V}$ for S1 and S2, respectively, is converted into two distinctive peaks as captured in CV of S3, S4, and S5. Enlightened by the phenomenon observed in $\mathrm{LiMn}_{2} \mathrm{O}_{4}$, that two distinct cathodic peaks correspond to a two-step insertion of $\mathrm{Li}^{+}$into a Li-rich and Li-depleted state ( $\mathrm{Lu}$ et al., 2014; Suo et al., 2015), these two distinct cathodic peaks 
A

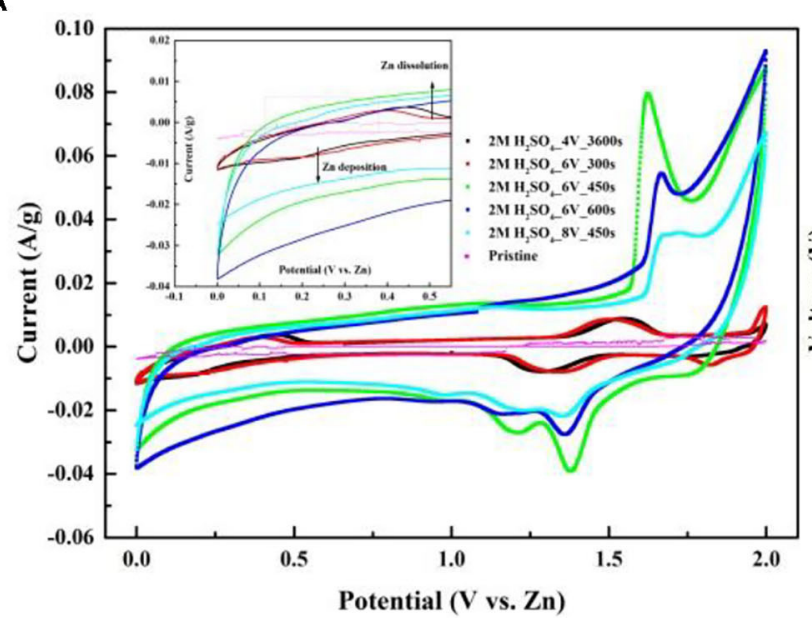

C

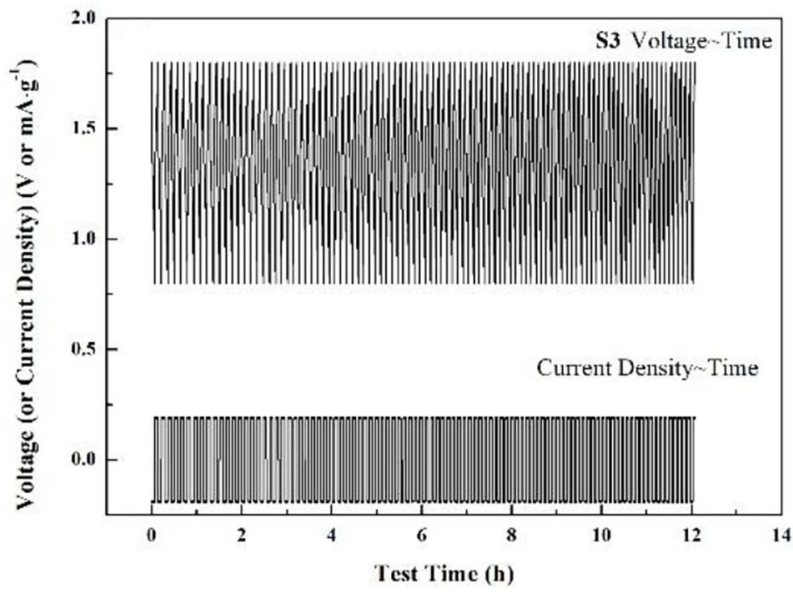

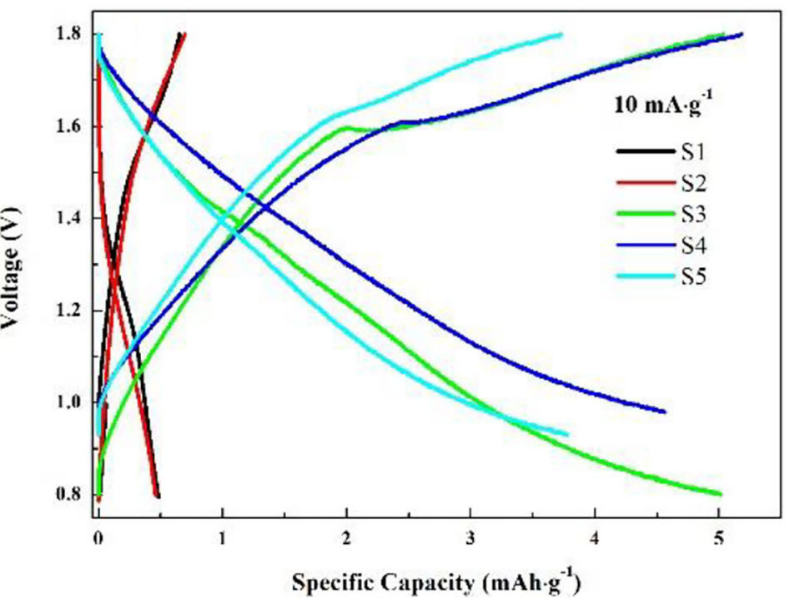

D

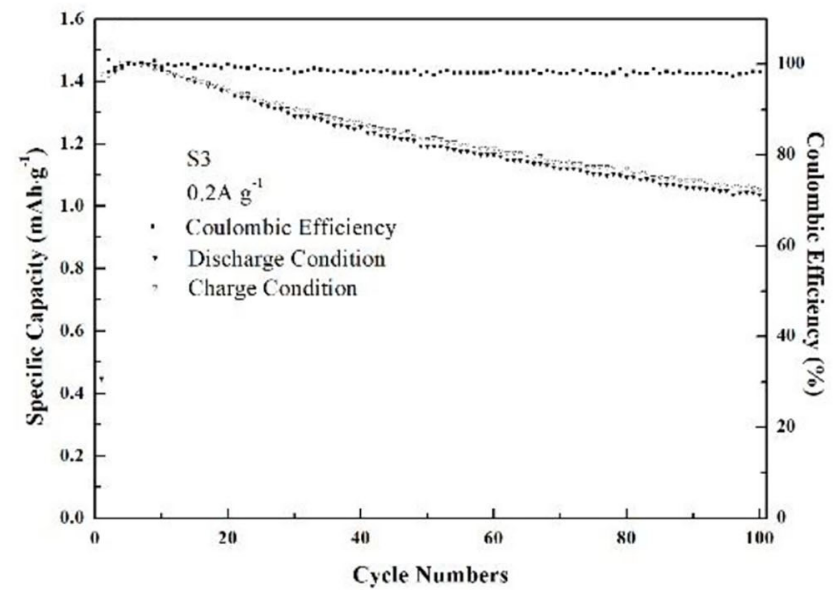

E $Z^{\prime}\left(\Omega g^{-1}\right)$

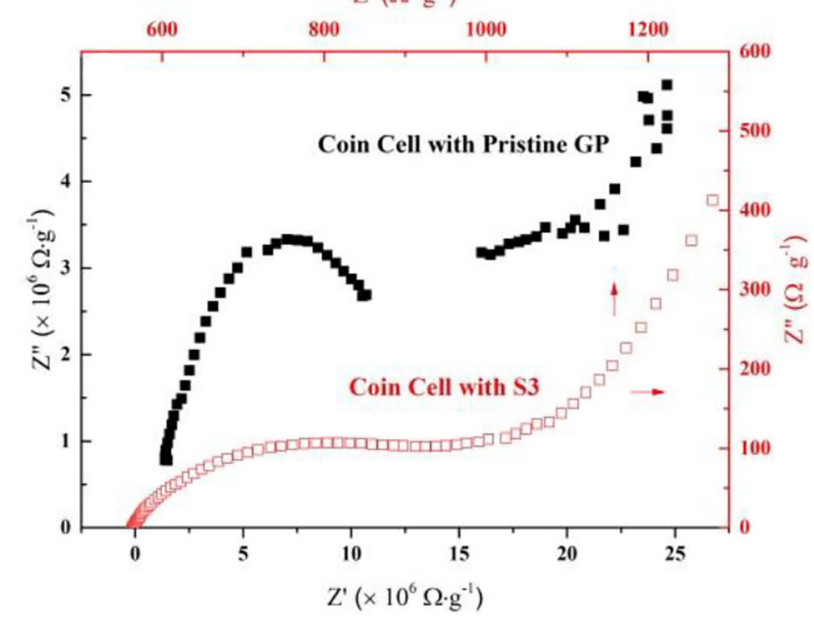

FIGURE 5 | (A) Cyclic voltammetry comparison among pristine GP, S1, S2, S3, S4, and S5. The measurement was conducted by using CR2032 coin-type cell with $\mathrm{Zn}$ foil as counter electrode and $1 \mathrm{M} \mathrm{ZnSO}_{4}$ as electrolyte. The scan rate was $1 \mathrm{mV} \mathrm{s}{ }^{-1}$; (B) Galvanostatic charge/discharge curves of AGP/Zn between 0.8 and $1.9 \mathrm{~V}$ at $10 \mathrm{~mA} \mathrm{~g}^{-1}$; (C) Gavanostatic cycling of S3 at $0.2 \mathrm{~A} \mathrm{~g}^{-1}$ for 100 cycles; (D) Cycling performance of the cell with S3 as cathode at $0.2 \mathrm{~A} \mathrm{~g}^{-1}$; (E) EIS Nyquist plots comparison between coin cell with pristine GP and S3. The data was captured under their respective open circuit potential. 
could be attributed to gradual insertion of $\mathrm{Zn}^{2+}$ into the nearsurface and deep interlayer of AGP. Because that the specific area of all these three samples show great enhancement as compared with the other two and pristine one in Figure 4. Furthermore, as can be seen in the enlarged curves (Figure 5A, inset), the redox couple for deposition/dissolution of $\mathrm{Zn}^{2+} / \mathrm{Zn}$ is less significant due to the improved capacitive behavior after the activation. This benefit is given by the increased specific surface area as shown in Figure 4.

In order to assess ZIB performance with AGPs, galvanostatic charge/discharge curves of $\mathrm{AGP} / \mathrm{Zn}$ between 0.8 and $1.9 \mathrm{~V}$ at $10 \mathrm{~mA} \mathrm{~g}^{-1}$ have been detected. From the comparison shown in Figure 5B, it points out that AGP of S3 shows the highest specific capacity of $5.0 \mathrm{mAh} \mathrm{g}^{-1}$ which is two orders of magnitude higher than the pristine one and one orders than S1 and S2. After the assessment, S3 is proved to be the optimized cathode in this study. Therefore, gavanostatic cycling of S3 at $0.2 \mathrm{~A} \mathrm{~g}^{-1}$ was conducted to evaluate its stability. As elaborated in Figure 5C, from the start to the end of 100 cycles, there is no changes on its voltage $\sim$ time profile which supports its good reversibility and high stability. Based on Figure 5C, coulombic efficiency of the cell with S3 has been calculated and was placed in Figure 5D. After 100 cycles of charge/discharge circulation, its coulombic efficiency can still attain at $96 \%$. Hence, concluded from above discussion, GP activated under S3 condition gives good ZIB performance. To elucidate the extraordinary improvement of ZIB performance by using S3, EIS comparison in Figure 5E between coin cell with NAGP and S3 has been discussed. From the interfacial standpoint, it can be seen that the electrode resistance of coin cell with NAGP is four orders of magnitude higher than the one with S3. The high contact resistance should be due to the hydrophobic nature of graphite without the treatment. In addition, the large semi-circle diameter of coin cell with NAGP also presents a high charge transfer resistance. This observation is actually in agreement with the CV conclusion, the large half peak width and low current density of which tells the sluggish kinetic process in coin cell with NAGP. Due to this high charge transfer resistance, the coin cell with NAGP also shows low specific capacity as compared with that of S3. To conclude, from an interfacial perspective, the improvements of using S3 should be contributed to by the increased hydrophilic property of GP after the treatment, hence decreasing the contact resistance and corresponding charge transfer resistance. Finally, the coin cell with S3 exhibits an advantageous ZIB performance in this study.

To reveal the interfacial behavior of $\mathrm{S} 3$ in $\mathrm{ZIB}$, the electrochemical impedance spectra of the coin cell under different voltage have been investigated and exhibited in Figure 6. The choice of voltage is based on the electrochemical process corresponding to CV of S3 in Figure 5A. The Nyquist plots in Figure 6A displays one depressed semi-circle which concatenates one semi-circle in mid frequency region, followed by a large semi-circle in low frequency at all voltages. The semicircle in low frequency is related to peaks in the corresponding frequency region in Figure 6B. To quantitatively analyze the electrochemical interfacial process during ZIB operation via S3, $\mathrm{Zn}$ foil, and $1 \mathrm{M} \mathrm{ZnSO}_{4}$, the equivalent circuit in Figure 2C compatible with below impedance spectra is adopted and the corresponding fitting parameters are listed in Table 2. In the table, parameter of $R s$ represents the series resistance from electrode, solution, and contact; charge transfer resistance $\left(R_{C T}\right)$ with a parallel constant phase element $(C P E)$ which relates to $\mathrm{Zn}^{2+} / \mathrm{Zn}$ reaction at the surface of the $\mathrm{Zn}$ foil along with extraction/insertion of $\mathrm{Zn}^{2+}$ from/into S3; the serial open circuit Warburg impedance $(W o)$ in the circuit reflects ion diffusion kinetics from electrolyte to the electrode/electrolyte interface. As shown, comparing parameters obtained at $1.25,1.38$, and $1.63 \mathrm{~V}$, $R_{S}, R_{C T}$, and Warburg impedance $W_{o}-R$ shows the lowest value at $1.63 \mathrm{~V}$. This decrease corresponds to the sharp peak in $\mathrm{CV}$ of S3 (Figure 5A), revealing the fast extraction of $\mathrm{Zn}^{2+}$ from S3 which possibly promotes the charge transfer rate for $\mathrm{Zn}^{2+}$ diffusion and $\mathrm{Zn}$ deposit. However, all these three values are high at $0.8 \mathrm{~V}$. Combining with Figure $\mathbf{5 A}$, a typical capacitive behavior is shown as the nature of carbon-based material. Therefore, the high resistance should originate from the double layer on the
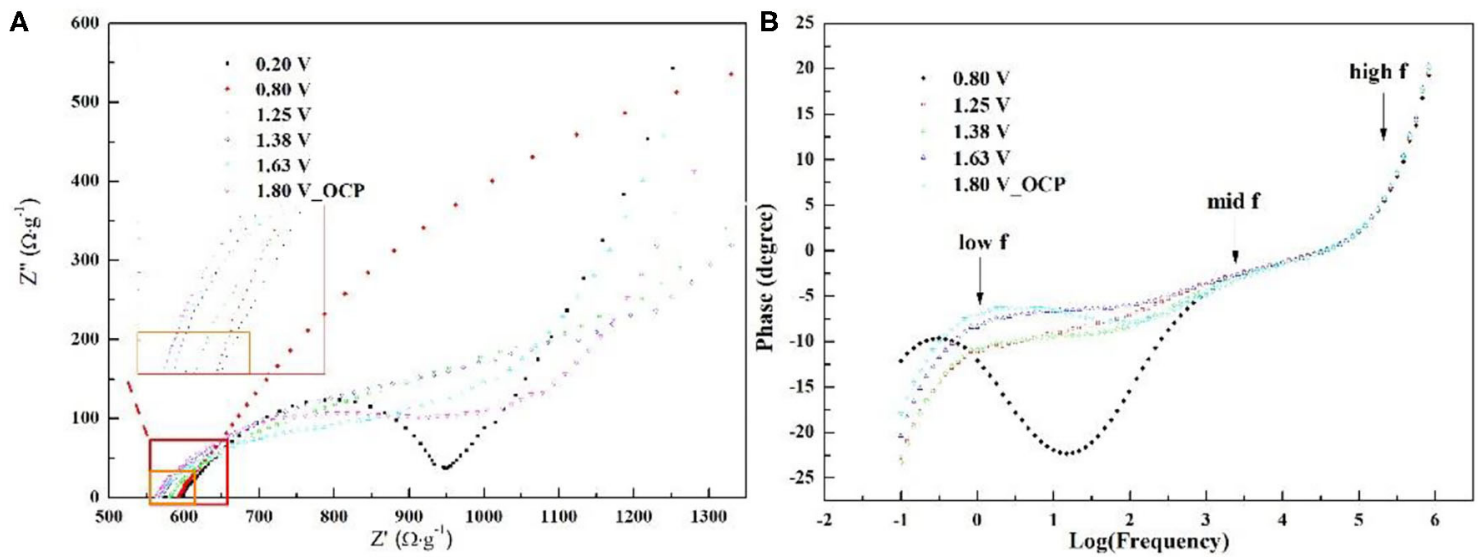

FIGURE 6 | Nyquist plots (A) and Bode plots (B) of the ZIB with S3, Zn foil, and $1 \mathrm{M} \mathrm{ZnSO}_{4}$ in a CR2032 coin under different voltage (the chosen voltage was based on the platform and peak location in CV of S3). 
TABLE 2 | List of ElS fitting parameters.

\begin{tabular}{|c|c|c|c|c|c|c|c|}
\hline $\begin{array}{l}\text { Voltage } \\
\text { v }\end{array}$ & $\begin{array}{c}R s \\
\Omega \cdot g^{-1}\end{array}$ & $\begin{array}{c}R_{C T} \\
\Omega \cdot \mathbf{g}^{-1}\end{array}$ & $\begin{array}{c}\text { CPE-T } \\
F \times \mathbf{g}^{-1}\end{array}$ & CPE-P & $\begin{array}{l}W_{O-R} \\
\Omega \cdot g^{-1}\end{array}$ & $\begin{array}{c}W_{O}-P \\
\mathrm{~s}\end{array}$ & $W_{0}-T$ \\
\hline 0.8 & 592.6 & 2128.7 & 0.053 & 0.64 & 8.48 & 0.001 & 0.30 \\
\hline 1.25 & 567.6 & 249.4 & 0.287 & 0.53 & 1377.78 & 4.917 & 0.34 \\
\hline 1.38 & 556.5 & 305.4 & 0.160 & 0.56 & 1359.57 & 4.413 & 0.36 \\
\hline 1.63 & 553.7 & 221.7 & 0.185 & 0.54 & 834.57 & 3.762 & 0.35 \\
\hline
\end{tabular}

electrode surface. Consistently, a minimum $C P E-P$ is obtained at $0.8 \mathrm{~V}$ due to the limited contribution from the double layer on near-surface. To conclude, during the operation window, the cell goes through a conversion from capacitive predominance to a fast charge transfer process involving extraction/insertion of $\mathrm{Zn}^{2+}$.

\section{CONCLUSION}

The interfacial effect of three kinds of inorganic mild electrolyte on ZIBs performance have been investigated by electrochemical techniques. The construction of ZIBs includes Zn foil, graphite paper, and the chosen electrolyte. Through the comparison, it reveals that $\mathrm{ZnSO}_{4}$ is the most preferred electrolyte among the chosen three. It provides faster $\mathrm{Zn}$ stripping/plating kinetics. And the electrolyte of $\mathrm{Zn}\left(\mathrm{CH}_{3} \mathrm{COO}\right)_{2}$ exhibited the most promising alternative in the $\mathrm{ZIB}$ system. However, $\mathrm{ZIB}$ with $\mathrm{Zn}\left(\mathrm{NO}_{3}\right)_{2}$ as electrolyte exhibits poor performance. Even though the overall ZIB performance based on pristine graphite paper presents limited specific capacity. Therefore, an electro-activation method has been adopted for the activation of graphite paper. After the optimization, through the comparison, it was found that sample $\mathrm{S} 3$, activated at $6 \mathrm{~V}$ for $450 \mathrm{~s}$ in $2 \mathrm{M} \mathrm{H}_{2} \mathrm{SO}_{4}$, displays outstanding

\section{REFERENCES}

Armand, M., and Tarascon, J. M. (2008). Building better batteries. Nature 451, 652-657. doi: 10.1038/451652a

Cheng, F., Chen, J., Gou, X., and Shen, P. (2005). High-power alkaline $\mathrm{Zn}-\mathrm{MnO}_{2}$ batteries using $\gamma-\mathrm{MnO}_{2}$ nanowires/nanotubes and electrolytic zinc powder. Adv. Mater. 17, 2753-2756. doi: 10.1002/adma.200500663

Choi, J. W., and Aurbach, D. (2016). Promise and reality of post-lithiumion batteries with high energy densities. Nat. Rev. Mater. 1:16013. doi: 10.1038/natrevmats.2016.13

Fan, J. X., Xiao, Q. Q., Fang, Y. B., Li, L., and Yuan, W. H. (2019) A rechargeable zn/graphite dual-ion battery with an ionic liquid-based electrolyte. Ionics 25, 1303-1313. doi: 10.1007/s11581-018-2644-X

Gui, Y., and Blackwood, D. J. (2015). Honey-comb structured $\mathrm{WO}_{3} / \mathrm{TiO}_{2}$ thin films with improved. J. Electrochem. Soc. 162, E205-E212. doi: 10.1149/2.0031510jes

Hwang, J. (2018). Symmetric cell electrochemical impedance spectroscopy of $\mathrm{Na}_{2} \mathrm{FeP}_{2} \mathrm{O}_{7}$ positive electrode material in ionic liquid electrolytes. J. Phys. Chem. C 122, 26857-26864. doi: 10.1021/acs.jpcc.8b09233

Kim, H., Hong, J., Park, K. Y., Kim, H., Kim, S. W., and Kang, K. (2014). Aqueous rechargeable li and na ion batteries. Chem. Rev. 114, 11788-11827. doi: $10.1021 / \operatorname{cr} 500232 y$

Konarov, A. K. A., Voronina, N., Jo, J. H., Bakenov, Z., Sun, Y. K., and Myung, S. T. (2018). Present and future perspective on electrode improvements. After the activation, firstly, the surface of S3 becomes rougher than the pristine one but intact as a whole rather than exhibiting the breaks seen in other samples; secondly, the coherency of its surface ensures a fast charge transfer kinetics reflected by $\mathrm{CV}$ with high current density and narrow half peak width; thirdly, the specific capacity based on CR2032 coin with S3 exhibits two orders of magnitude higher than the one with pristine graphite paper. Moreover, coin cell CR2032 with S3 also shows the highest specific capacity in this study.

\section{DATA AVAILABILITY STATEMENT}

All datasets generated for this study are included in the article/supplementary material.

\section{AUTHOR CONTRIBUTIONS}

YG designed experiments, carried out experiments, analyzed experimental results, and wrote the manuscript. BF supported required experimental instruments and helped revising the manuscript. YL supported required experimental instruments, publish payment, and helped revising the final manuscript. All authors contributed to the article and approved the submitted version.

\section{FUNDING}

This work was supported by Key Laboratory of Hubei Province for Coal Conversion and New Carbon Materials, School of Chemistry and Chemical Engineering, Wuhan University of Science and Technology, P. R. China (Project no. 1050010) and the National Nature Science Foundation of China (Project no. 21706198). materials for rechargeable zinc-ion batteries, ACS Energy Lett. 3, 2620-2640. doi: 10.1021/acsenergylett.8b01552

Lee, B., Lee, H. R., Kim, H., Chung, K. Y., Cho, B. W., and Oh, S. H. (2015). Elucidating the intercalation mechanism of zinc Ions into $\alpha$ $\mathrm{MnO}_{2}$ for rechargeable zinc batteries. Chem. Commun. 51, 9265-9268. doi: 10.1039/C5CC02585K

Lee, B., Seo, H. R., Lee, H. R., Yoon, C. S., Kim, J. H., Chung, K. Y., et al. (2016). Critical role of ph evolution of electrolyte in the reaction mechanism for rechargeable zinc batteries. Chem. Sus. Chem. 9, 2948-2956. doi: $10.1002 /$ cssc. 201600702

Li, G., Yang, Z., Jiang, Y., Jin, C., Huang, W., Ding, X., et al. (2016). Towards polyvalent ion batteries: a zinc-ion battery based on NASICON structured $\mathrm{Na}_{3} \mathrm{~V}_{2}\left(\mathrm{PO}_{4}\right)_{3}$. Nano Energy 25, 211-217. doi: 10.1016/j.nanoen.2016. 04.051

Li, S., Dong, Y., Xu, L., Xu, X., He, L., and Mai, L. (2014). Effect of carbon matrix dimensions on the electrochemical properties of $\mathrm{Na}_{3} \mathrm{~V}_{2}\left(\mathrm{PO}_{4}\right)_{3}$ nanograins for high-performance symmetric sodium-ion batteries. Adv. Mater. 26, 3545-3553. doi: 10.1002/adma.201305522

Lin, M. C., Gong, M., Lu, B., Wu, Y., Wang, D. Y., Guan, M., et al. (2015). An ultrafast rechargeable aluminium-ion battery. Nature 520, 324-328. doi: 10.1038/nature 14340

Liu, Z., Bertram, P., and Endres, F. (2017). Bio-degradable zinc-ion battery based on a prussian blue analogue cathode and a bio-ionic liquid-based electrolyte. J. Solid State Electrochem. 21, 2021-2027. doi: 10.1007/s10008-017-3589-0 
Liu, Z., Pulletikurthi, G., and Endres, F. (2016). A prussian blue/zinc secondary battery with a bio-ionic liquid-water mixture as electrolyte. ACS Appl. Mater. Interfaces 8, 12158-12164. doi: 10.1021/acsami.6b01592

Lu, J., Zhan, C., Wu, T., Wen, J., Lei, Y., Kropf, A. J., et al. (2014). Effectively suppressing dissolution of manganese from spinel lithium manganate via a nanoscale surface-doping approach. Nat. Commun. 5:5693. doi: $10.1038 /$ ncomms6693

Lu, Y., Goodenough, J. B., and Kim, Y. (2011). Aqueous cathode for next-generation alkali-ion batteries. J. Am. Chem. Soc. 133, 5756-5769. doi: $10.1021 /$ ja201118f

Muldoon, J., Bucur, C., and Gregory, T. (2014). Quest for nonaqueous multivalent secondary batteries: magnesium and beyond. Chem. Rev. 114, 11683-11720. doi: $10.1021 / \operatorname{cr} 500049 y$

Pan, H., Shao, Y., Yan, P., Cheng, Y., Han, K. S., Nie, Z., et al. (2016). Reversible aqueous zinc/manganese oxide energy storage from conversion reactions. Nat. Energy 1:16039. doi: 10.1038/nenergy.2016.39

Parker, J. F., Chervin, C. N., Pala, I. R., Machler, M., Burz, M. F., Long, J. W., et al. (2017). Rechargeable nickel-3D zinc batteries: an energy-dense, safer alternative to lithium-ion Science 356, 415-418. doi: 10.1126/science. aak9991

Ponrouch, A., Frontera, C., Barde, F., and Palacin, M. R. (2016). Towards a calcium-based rechargeable battery. Nat. Mater. 15, 169-172. doi: $10.1038 /$ nmat4462

Qiu, H. Y., Du, X. F., Zhao, J. W., Wang, Y. T., Ju, J. W., Chen, Z., et al. (2019). Zinc anode-compatible in-situ solid electrolyte interphase via cation solvation modulation. Nat. Comm. 10:5374. doi: 10.1038/s41467-01913436-3

Suo, L., Borodin, O., Gao, T., Olguin, M., Ho, J., Fan, X., et al. (2015). "Water-inSalt" electrolyte enables high-voltage aqueous lithium-ion chemistries. Science 350, 938-943. doi: 10.1126/science.aab1595

Wang, C., Appleby, A. J., and Little, F. E. (2001). Electrochemical study on nano$\mathrm{Sn}, \mathrm{Li}_{4.4} \mathrm{Sn}$ and $\mathrm{AlSi}_{0.1}$ powders used as secondary lithium battery anodes. J. Power Sources 93, 174-185. doi: 10.1016/S0378-7753(00)00576-0

Wang, F., Borodin, O., Gao, T., Fan, X. L., Sun, W., Han, F. D., et al. (2018). Highly reversible zinc metal anode for aqueous batteries. Nat. Mat. 17, 543-549. doi: 10.1038/s41563-018-0063-Z

Wang, Z., Li, H., Tang, Z., Liu, Z., Ruan, Z., Ma, L., et al. (2018). Hydrogel electrolytes for flexible aqueous energy storage devices. Adv. Funct. Mater. 28:1804560. doi: 10.1002/adfm.201804560
Whittingham, M. S. (2004). Lithium batteries and cathode materials. Chem. Rev 104, 4271-4302. doi: 10.1021/cr020731c

Xu, C., Li, B., Du, H., and Kang, F. Y. (2012). Energetic zinc ion chemistry: the rechargeable zinc ion battery. Angew. Chem. Int. Ed. Engl. 51, 933-935. doi: 10.1002/anie.201106307

Yabuuchi, N., Kubota, K., Dahbi, M., and Komaba, S. (2014). Research development on sodium-ion battery. Chem. Rev. 114, 11636-11682. doi: $10.1021 / \mathrm{cr} 500192 \mathrm{f}$

Yamamoto, T., and Shoji, T. (1986). Rechargeable $\mathrm{Zn}\left|\mathrm{ZnSO}_{4}\right| \mathrm{MnO}_{2}$-type cells. Inorg. Chim. Acta 117, L27-L28. doi: 10.1016/S0020-1693(00)82175-1

Yang, C., and Lin, S. (2002). Improvement of high-rate capability of alkaline $\mathrm{Zn}-\mathrm{MnO}_{2}$ battery. J. Power Sources 112, 174-183. doi: 10.1016/S0378-7753(02)00354-3

Yuan, D., Manalastas, W. Jr,, Zhang, L. P., Chan, J. J., Meng, S. Z., Chen, Y. Q., et al. (2019).Lignin@ nafion membranes forming zn solid-electrolyte interfaces enhance the cycle life for rechargeable zinc-ion batteries. ChemSusChem 12, 4889-4900. doi: 10.1002/cssc.201901409

Zhang, N., Cheng, F. Y., Liu, Y. C., Zhao, Q., Lei, K. X., Chen, C. C., et al. (2016). Cation-deficient spinel $\mathrm{ZnMn}_{2} \mathrm{O}_{4}$ cathode in $\mathrm{Zn}\left(\mathrm{CF}_{3} \mathrm{SO}_{3}\right)_{2}$ electrolyte for rechargeable aqueous zn-ion battery. J. Am. Chem. Soc. 138, 12894-12901. doi: $10.1021 /$ jacs.6b05958

Zhao, H., Xu, J., Yin, D., and Du, Y. (2018). Electrolytes for batteries with earth-abundant metal anodes. Chem. Eur. J. 24, 18220-18234. doi: $10.1002 /$ chem. 201802438

Zhao, J., Ren, H., Liang, Q. H., Yang, D., Xi, S. B., Wu, C., et al. (2019). Highperformance flexible quasi-solid-state zinc-ion batteries with layer-expanded vanadium oxide cathode and zinc/stainless steel mesh composite anode. Nano Energy 62, 94-102. doi: 10.1016/j.nanoen.2019.05.010

Conflict of Interest: The authors declare that the research was conducted in the absence of any commercial or financial relationships that could be construed as a potential conflict of interest.

Copyright (c) 2020 Gui, Lei and Fan. This is an open-access article distributed under the terms of the Creative Commons Attribution License (CC BY). The use, distribution or reproduction in other forums is permitted, provided the original author(s) and the copyright owner(s) are credited and that the original publication in this journal is cited, in accordance with accepted academic practice. No use, distribution or reproduction is permitted which does not comply with these terms. 